\title{
Cultural Language and Commercials: Cross- cultural Content Analysis of Commercials between Almarai`and Real California Cheese
}

\author{
Wafa Moh`d Qtaishat \\ The University of Jordan, Amman, Jordan \\ Dania Ahmad Al-Hyari \\ The University of Jordan, Amman, Jordan
}

\begin{abstract}
Advertisements direct the consumers to focus on the products; it changes their mind and persuades them to buy the products which can be done by using certain lexical choices or gestures. Therefore, the researchers will compare two cultures; the Arabs culture especially the Gulf area and the Western culture especially the American culture by using five commercials of Almarai's company that represents the Arab part with another five American commercials from Real California Cheese company "The Happy cow from California" that represents the American culture. In addition, the researchers will look at commercials which exist in the two parts of the world as "Snickers" and "Philadelphia cheese" where the reader can notice some similarities and differences between the American culture and the Arab culture. The commercials in this paper are specified in food commercials. Finally, the researchers will focus on how the language is used in the commercials and how some of the standard of textuality such as cohesion, coherent and informativity are used.
\end{abstract}

Index Terms - advertisements, Arabs culture, American culture, the standard of textuality

\section{INTRODUCTION}

The word advertisement is derived from a Latin verb which means (to turn towards). Advertising communication can be seen as a social activity that functions to sell products. Advertisements lead the consumers to focus on the products; it will change their mind and persuade them to buy them if they really need the product or not. The phenomenon of advertising has been studied in numerous disciplines such as marketing, sociology, cultural anthropology, social psychology, semiotics and cultural studies. The most are that has been studied is "the analysis of mass media advertising content to gain insights into how cultural factors affect advertising strategies and expressions; how cultural values, norms and stereotypes are reflected in advertising; how advertising creates meanings and affects the audience and the larger society over time." (Bansal, 2009) Advertisements reflect culture according to that there are different advertisements from one country to another. For example, International companies have different advertisements for the same product depending on the country in which the advertisement is shown.

In addition, every commercial conveys some information, it presents a list of information cues which include the price, the packaging or shape, the quality, the guarantees or warrantees, performance, safety, components or contents, nutrition, availability, independent research, special offers, company-sponsored research, taste and new ideas.

Downing modifies that studying advertisements as a discourse type "plays with the evocation of imaginative situations has been pointed out recently by several authors" as Carter and Nash, 1990, Cook, 1992, 1994 and Semino, 1997. Also, He explains that Semino has noticed that "advertising is a genre where the setting up of vivid contexts and discourse situations is often crucial to the achievement of the text producers' goals"(Downing, 2000). Downing and Bezuidenhout clarify Cook`s features of context in advertising discourse; starting with the substance which is the physical material of advertisements, music and pictures, paralanguage which consists of voice, gesture, type and size of letters, situation which is "the properties and relations of objects and people in the vicinity of the text, as perceived by the participants" (Bezuidenhout, 1998), co-text, intertext, participants and function which is the intentions of both senders and receivers. According to him Cook defines discourse as "text and context together, interacting in a way which is perceived as meaningful and unified by the participants (who are both parts of the context and observers of it)." (Downing, 2000) For that Bezuidenhout defines advertisement discourse as text occurring within a specific context.

Also, Bezuidenhout modifies that advertisements "always rely on the relation between the text and its context; the one cannot survive without the other... the context of the advertisement determines how the receivers will perceive the message. The context is embedded in a specific culture, whether it is a language-related culture or a sub-culture." (Bezuidenhout, 1998) Also, he modifies that the task of discourse analysis is to identify the cultural aspects and determine their role in the persuasive advertisements in view of transferring them in the translation process.

Also, Magalhaes (2005) examines textual and semiotic aspects of advertisements to critical discourse analysis. His focus is on the gender identity, "both the feminine and the masculine are represented discursively in their heterogeneity; 
the feminine is represented as a commodified body. The masculine is linked with power, but with fashion too." (Magalhaes, 2005) Gilly (1988) studies the gender portrayals in advertising of the United States, Australia and Mexico; the results show that the use of the sex role is present in the three countries; however, United States and Mexico use the sex role more than Australian.

Magalhaes explains the semiotic aspect as the ways in which photos represent women and men. Also, he divides the semiotic aspect into four different kinds; pictures, abstract shapes, words and letters. Some qualitative researches have used semiotics and other interpretative methods to analyze the linguistic content and the visual content as Barthes (1979), Vestergaard and Schroder (1985) and Williamson (1978). He states that semiotics is a new interdisciplinary approach, "this new approach can be extended to a cross cultural study of advertising to examine both verbal and visual content" (Ahmed, 1996) because it can be used in examining the visual content of advertising.

According to Valmoria, studies which investigate the advertisements content "revolve on two major elements" (Agatep-Valmoria, Myra Vina D., 2007) which can be described as informational advertising 'what is said' and persuasive advertising 'how it is said'; first, the strategy element "commenced in the late 1970s when the Federal Trade Commission of the United States recognized the growing deception in marketplace with regard to the claims of marketers. A survey on deception cases filed in court showed that information in advertisements or lack of it is a way for marketers to exercise the capacity or tendency to deceive" this strategy element studies 'what is said'. The second element is the execution element which is concerned with 'how it is said'.

Resnik and Stern (1977), every commercial transmits some information by transmitting visual and audio stimuli to offer significant indications. They present a list of information cues which contain the price, the packaging or shape, the quality, the guarantees or warrantees, performance, safety, components or contents, nutrition, availability, independent research, special offers, company-sponsored research, taste and new ideas.

\section{CUltures AND Advertisements}

Cultures play an important role in the international advertisements. Bansal and Khattri define culture according to Engel, Blackwell, and Miniard as "complex values, ideas, attributes, and other meaningful symbols that serve humans to communicate, interpret, and evaluate as members of society." (Gully, (1996-97)) Also, they mention that Stanton, Etzel, and Walker define culture as "symbols and artifacts" which can be done by the people who live in that culture and these symbols can be moved from generation to generation as determinants and regulators of human behavior.

In addition for that, Yang states that objects, ideas and concepts "are employed by advertisers to manipulate and persuade the receivers to simulate consumer behaviors depicted in the advertisements." (Yang, 2006) He focuses on the translation of cross-cultural advertisements by explaining the gap between the source and the target language in the translation of the international advertisements. He concludes that translation "allows for specific variations when applied to particular cultures, taking into account the specific cultural conventions and the expectations of the members of a particular culture. Thus, as long as the translation of advertisements works admirably, and produces equivalent pragmatic effect, it is more likely to come up with the most persuasive advertisements in their respective language." (Yang, 2006)

Also, Ahmed counts in his research that the previous studies which investigates the cross-culture content analyses of advertising as; Weinberger and Spotts (1989) who analyze the information content of British and U.S. television advertising and they conclude that U.S. advertising contained more information cues than the British advertising. However Resnik and Stem show that the level of information "has increased in U.S. over a decade." Also, Biswas, Olsen and Carlet (1992) compare the content analysis of information content and emotional appeals between United States and France. However, Cutler and Javalgi (1992) who compare between United Kingdom, United States and France in the cross cultural analysis of the visual components of print advertisements. They conclude that there are greater differences between countries than similarities in term of various visual components in advertising.

In addition, Belk and Bryce (1986) make a comparison between Japan and the United States; they try to investigate the culture differences in advertising according to materialism and individualism. The results in their study are that the U.S. advertisements have more emphasis on individual determinism and materialism.

Valmoria, Lin and Salwen (1995) reclassify the information cues into two major parts; rational and emotional. Rational appeal consists of price, quality, performance, safety and guarantees and warranties and emotional appeal consists of taste, packaging and new ideas. Valmoria uses Walliser study to modify some studies on cross cultural comparison of information content (Agatep-Valmoria, Myra Vina D., 2007);

$\begin{array}{lcl}\text { Country Average } & \text { Number of Cues } & \text { Author } \\ \text { Australia } & 1.88 & \text { Dowling (1980) } \\ \text { Canada } & 1.47 & \text { Johnstone et al. (1987) } \\ \text { China } & 1.90 & \text { Keown et al. (1987) } \\ \text { France } & 2.40 & \text { Schroeder (1991) } \\ \text { Germany } & 1.95 & \text { Walliser (2001) } \\ \text { India } & 2.30 & \text { Ahmed (2000) } \\ \text { Ireland } & 2.20 & \text { Ward and McQuirk (1987) } \\ \text { South Korea } & 1.86 & \text { Keown et al. (1987) }\end{array}$



Spain
1.38
US
1.28
Bigne (1993)
Resnik and Stern (1977), Johnstone et al. (1987)

Furthermore, according to Bansal and Khattri (2008) "Cross-cultural analysis of advertising can identify specific differences and similarities in advertising strategies, expressions, and manifest cultural values, norms and stereotypes of the target audience and the larger culture. Such findings may be used to address the question of whether the same strategies and expressions can be used in international advertising, and whether the values, attitudes, desires and tastes of consumers around the world are converging". They divide the world into two cultures; high context cultures which include the Middle East, Asia, India, Africa and South America and low context cultures which include north America and western Europe. Also, they describe the both cultures; starting with the high context culture as more relational, collectivist, intuitive, and contemplative. Also they say that "people in these cultures emphasize interpersonal relationships..." and that "These cultures are collectivist, have a preference for group harmony and consensus to individual accomplishment." (Bansal, Khattri, 2008) However, the low context cultures are more logical, linear, individualistic, and action-oriented. In addition for that Bansal and Khattri use the McDonalds advertisements one from America and another one from India to show that collectivistic is versus individualistic; they modify that the high context cultures are more collectivism than the low context cultures which tend to be more individualism. They explain that the collectivist cultures try to reflect the happy time which is spent with family and friends as their dominant values. However, the individualist culture reflects the "freedom and personal time" to imply "relaxation and time spent by oneself." (Bansal, Khattri, 2008)
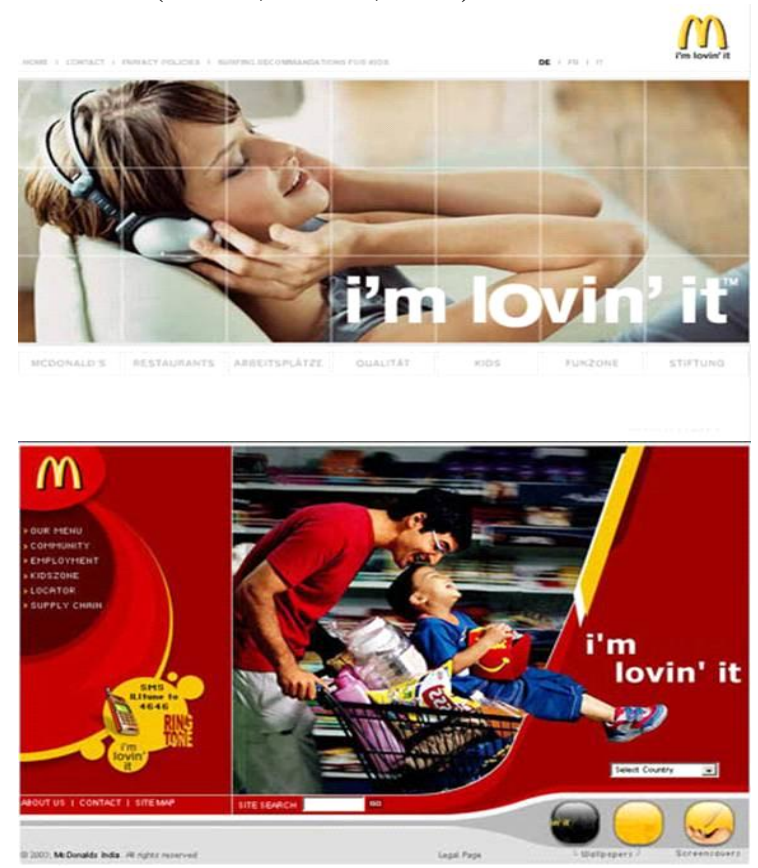

So the American $\mathrm{AD}$ reflects the image of individuals enjoying themselves with music and relaxation. And from the second $\mathrm{AD}$ one can understand that McDonalds is "a family restaurant in India where people can come and have a good time. Hence the user imagery is that of families having fun time at McDonalds" (Bansal, Khattri, 2008). This is a result and reflection of the collective society that India has.

Perry, Motley and Lewis (2008) have written about Islam and advertising. They explain that there a number of studies that examine the role of the religion in the advertisements as Rice and al-Mossawi (2003) who modify the type of the Islamic advertisements that might be appropriate for Muslims using a framework that relates basic Islamic values to advertising.

"Television advertising has a very strong impact on our society. The advertisements in a country actually depict its cultural values." (Jabeen, 2011) Also, Jabeen modifies that different brand use television advertisement and other marketing activities as means of promoting culture. And the reason for that is to develop a prestige of a brand among customers who respect such values in order to make it preferable by the customers. Jabeen gives examples from her region which is Pakistan that there are some advertisements which promote their culture values "while other are depressing them." (Jabeen, 2011) She explains that in their country they have popular and old brands which try to reflect their traditions in the advertisements. She adds that some brands use to make special campaigns during various religious festivities and other occasions. In addition, she explains that most of these advertisements have capitalized the opportunity of featuring traditional family values in their advertisements. These advertisements usually emphasize the importance of joint family system, eating and dining together, getting together at tea time in the evening and respecting our elders to attract customers. 


\section{METHODOLOGY}

Advertisements direct the consumers to focus on the products; it changes their mind and persuades them to buy the products and this can be done by using certain lexical choices or gestures. Also, the researchers will focus on some of the standard of textuality such as cohesion, coherent and informativity. Also, the researchers will compare two cultures; the Arabs culture especially the Gulf area and the western culture especially the American culture by using five commercials of Almarai`s "المر اعي company to represent the Arab part and another five American commercials from Real California Cheese company "The Happy cow from California" to represent the American culture. In addition, the researchers will look at commercials which exist in the two parts of the world as "Snickers" and "Philadelphia cheese" where the reader can notice some similarities and differences between the Arab culture and the American. The commercials in this paper are all food`s commercial which are taken from the YouTube site.

\section{ANALYSIS}

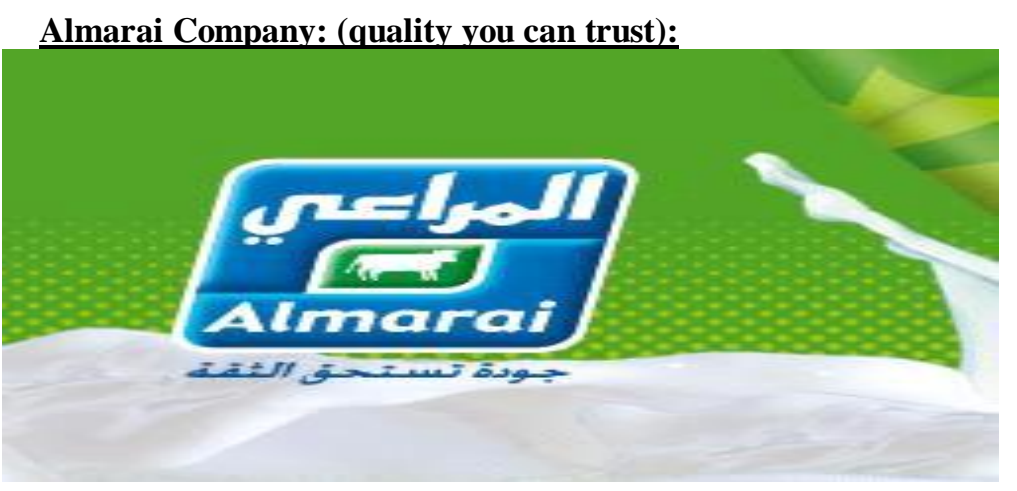

Almarai ${ }^{1}$ is the largest integrated dairy foods company in the Middle East which was established in the Kingdom of Saudi Arabia in 1976. As a researcher, I use this company as a model for the Middle East culture especially for the Gulf area because the commercials are done to the Gulf area as the addressee for them. So, for that the commercials do respect their culture. The researchers have five commercials to analyze and to reflect the Arabic Culture from them.

\section{The first Commercial:}

A child who is like five years old is running to his family who are in a picnic. Once the child arrives to his family, the grandmother gives him a glass of Al Maria juice which is supposed to be given to his father not the child. In that moment the father says a proverb which is "the dearest of the son is his son (the grandchild)". Then the narrator says "and the dearest of fruits is the fruit juice" then he says "Almarai juice... as you like it".

This commercial lasts for only seventeen seconds which in the beach with the sound of the sea gull. This commercial represents the family bond (the grandmother, her son, the grandchild and a woman who is maybe the son`s wife). Also, It reflects an Arabic proverb which can be used alone to reflect their culture. In addition, the women dress a veil (Hijab) to represent the Islamic Culture. Also, their accents show that the commercial is addressed to Arabs especially who live in the Gulf.

This advertisement is coherent because it is related to reality. Also, cohesion is achieved for example by using the conjunction "and" by the narrative to complete the father's role. This ad is not shown to inform the receiver the content of the juice or the price but it shows that this juice is better than the fruit itself because this juice is what "you" like.

\section{The second commercial:}

A mother who is celebrating her son`s graduating in their home. In celebrations, one knows that there are many kinds of foods and deserts but in this commercial the focus is on the juice while the mother is pouring a glass for her son. In that moment, the father arrives from work because he holds a business bag so the son runs to his father and the mother passes a gift to the father without letting the child notice. When the father gives the gift to the son, the mother gives the father a glass of juice and he says: "behind every great man is a great woman". The narrator concludes by saying that "behind every great juice is a great fruit... Al Marai juice... as you like it."

In this commercial, one can notice the happy family and the use of Al Marai juice completes the happiness. Also, it reflects the Arabic Culture where the father is supposed to work and the mother is supposed to take care of the house. In addition the father dresses the traditional customs and the mother dresses the hijab. The coherence and cohesion are achieved in this commercial. The informativity is only the idea that in order to make a great juice one needs great fruits.

\section{The third commercial:}

Well cooked rice, chicken are shown on a table with a narrator who is a woman talking to women saying that in order to cook a tasty food you need to have Al Marai butter, a good cooker, then put the butter in the pan, add a lacing of love and finally you and your family will enjoy the taste. After that, the narrator describes the Al Marai butter by saying "Al Marai is all in all".

\footnotetext{
${ }^{1}$ See www.lordofthebrush.com
} 
This commercial lasts for thirty seconds. It represents the Arabic culture, for example the use of the rice which is an essential component in the Gulf area and in the Arab world in general. Also, the need to be a great cooker is also an essential condition for the Arabic women. The cohesion is achieved in this ad but the coherent can be said that it is violated but with a little imagination it can be fixed as if the listener will downgrade the text; for example, adding a lacing of love can be a species or something else. However, Arabs know that the cooker must love what they cook and cook with passion. So, Arabs can understand it because it is a common knowledge for them. In addition for that, this commercial can be used as if it is a teaching program which teaches people how to cook. This commercial unlike the first commercials does not use the picture of the family to reflect some aspects of the Arabic tradition.

\section{The fourth commercial:}

A lady is in the kitchen talking on the telephone saying that "you still need one hour to have launch so I am going to take a little snack." She starts eating Al Marai cheese first with biscuits then with chips after that with vegetables and finally with using a spoon. In every time she wants to eat, she tries to prevent herself from eating but the taste of the cheese is stronger than her well. She takes out the cheese from the refrigerator four times in forty six seconds, however, one can notice that this cheese is tasty and healthy; first, the lady is slim and the food that exist in the refrigerator are healthy foods only. After that, the lady asks the waiter to bring her a glass of water only and in that moment her friends look upset from her because she is supposed to have her lunch with them.

The researchers consider this commercial can be used in both cultures but the lady and her friends must change their outfit. Also, the camera makes zoom on the word /baladuna/ "our country" which is written on the bottle. In addition the word /tasbera/ "snack" can be used as an aspect of the Gulf area because they have many kinds of food that are represented as /tasbera/, for example; l'usine. The informativity is achieved in this commercial by representing the different ways that Al Marai cheese can be eaten with, also how much it's taste is irresistible. In addition, the cohesion and coherence are achieved. Here, the focus is on the acting (the picture) more than the words themselves trying to transfer the irresistible taste to the receivers to persuade and to motivate them to try this product.

\section{The fifth commercial:}

A mosque background which resembles the Andalusia architecture and the night light are represented. Suddenly lantern swags from the ceiling, however, this lantern is not a normal one but it is Al Marai juice instead as if it is the light in the midnight or it is like the energy which one needs in fasting and praying. There is no a sound effect or narrator sound in the commercial. For that, this commercial is expressed only by the use of the picture which has the Almarai s logo and slogan which is a sentence or phrase which through repeated usage is designed to become identified with the advertiser's product or service. Also, in the picture there is a wish to enjoy Ramadan and an advice to make your fast healthy and powerful.

This commercial as the previous commercials does not give any information about the component of the juice. It only reflects that this juice will help you in Ramadan and it will make your fast healthy and powerful. The use of the orange juice specifically can imply the freshness and powerful energy that can be achieved by the vitamin $\mathrm{C}$. The coherence and cohesion are achieved because the idea of Ramadan is acceptable in the Arabs world but if this commercial appear for example in a non Muslim country it will not be acceptable but also it will be rejected by the people who live there. So, the use of the Ramadan is a clear representative of the Muslims culture.

\section{Real California Cheese: (it's the cheese):}

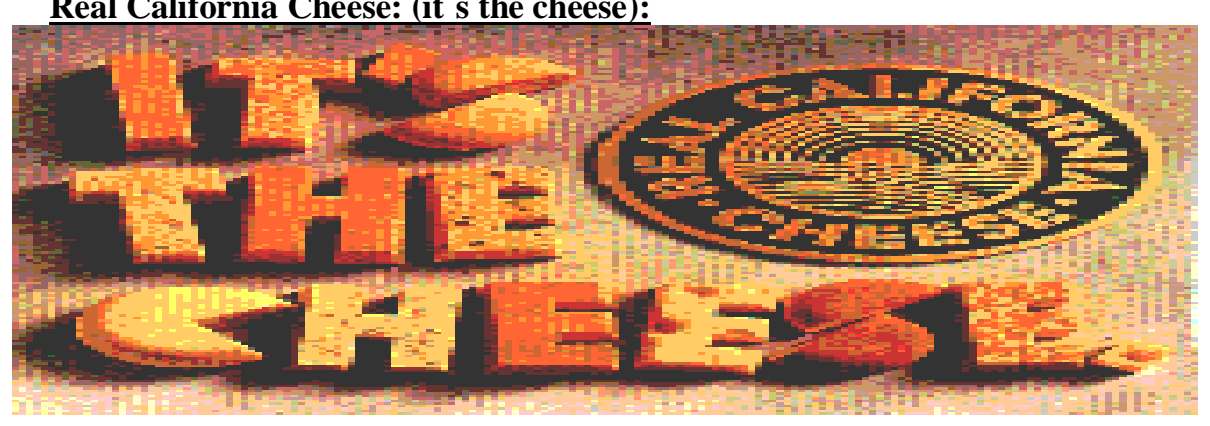

The Real California Cheese Seal was established in 1984. The seal was created with heavy participation from the California Milk Advisory Board which was the first U.S. dairy advisory board to generate a set of industry standards for quality and excellence in cheese production ${ }^{2}$.

\section{The first commercial:}

Two cows are walking in a very nice field and suddenly a black bull comes to to the two cows says: "ladies /my name/ is Bob I am a French bull" one of the cows says: "wow... French bull...uh... you must feel lonely so far from home... lucky you Dayan speaks fluent French here." The other cow says a French statement; however, the bull does not understand for that he says nothing unless "hha... that's..." in that moment the two cows start laughing loudly. Also, in that moment another bull appears starting the conversation by saying "bounjour ladies..." so the first bull says: "forget it Bell" with the sound of the two cows laughing as a background.

\footnotetext{
${ }^{2}$ See www.sportsnetwork.com
} 
This theme is not acceptable to be shown in a Saudi Arabia specially; however, as a researcher, we think it is there but it is not presented in the television. So, we think this idea is more acceptable in the western culture. Also, the amount of information is higher that the Arabic sample. This commercial which lasts for twenty eight seconds shows that these "happy" cows are special and because of that their milk is used. Also, the last picture represents the whole products that this company produces; different kinds of cheese, milk, butter, ice cream and yogurt without forgetting to decorate the table with green and red grapes which can be used as a symbol of wine to prove this the researcher will quote an article (Wine and Cheese: California Style by Ron Kapon). In addition there is the website address if someone wants to know more details and so on. According to that, we think the use of the website link represents the western culture in general more the eastern one because they are used to use the technology more than the Arabs.

The second commercial ${ }^{3}$ :

Cow: "ok... again... who rules?"

Bull: "cows rule"

Cow: "and why the cows rule?"

Bull: "because they are the farm masters"

Cow: "and do you think they are pretty?"

Bull: "yes... (With very bored tone)"

Cow: "yes what"

Bull: "yes I think the cows are pretty..."

Cow: "oh... do you want to marry a cow?"

Bull: "look can I just have the ball back (with serous intonation)"

Cow: "oh... this ball" with the sound that the ball falls in water.

Bull: "wow... ok, she is on our team"

Then the narrator ends by saying that "great cheese comes from happy cows... happy cows come from California.... Real California Cheese."

This commercial lasts for thirty seconds only in a very nice landscape; it has the idea that females try to impose their authority which can be seen in both cultures. In addition, the producer wants to reflect the power of the cows by kicking the ball for a far distance. This idea breaks the stereotype about females that they are pleasant and not powerful and this idea exists in both culture but it exists more in the eastern culture. Cohesion and coherent are achieved, also informativity too. This commercial as the first one, it has the website link.

\section{The third commercial:}

A cow starts singing a happy song then a group of cows start singing with her suddenly an old woman steps out from the house to dust off the towel. So, the first cow makes the sound of "sh... sh". The woman looks at the cows for two seconds then she gets back to the house. After that, the cows starts to sing again and the narrator ends this commercial by saying that "great cheese comes from happy cows... and happy cows from California... real California cheese.. it's the cheese."

This commercial can be seen in both cultures but in these commercials the focus is on the feminine aspect more than the masculine one. This commercial and the first two are unaccepted in our natural knowledge because we do not think that cows can sing like a human sound which can be represented as high level of informativity because it's not expected. This the first commercial from this company that the researcher has noticed that does not have the website link as the previous commercials.

\section{The forth commercial:}

A group of cows who is looking at a cow that comes to them, they say: "hey, she is the new girl... this could be interesting..." then the conversation starts between them asking her about this place. So, she reflects her happiness and gladness that there is no snow. However, the cows do not understand what is the meaning of snow but they think that she is has a problem because she is not used to talk with other cows. After that, the narrator ends the commercial by saying that: "great cheese comes from happy cows... and happy cows from California... real California cheese... it's the cheese."

This commercial which lasts for thirty five seconds can be presented in both cultures. The producer wants to show that how really suffers is not like who is not; the new cow has suffered from snow unlike the other cows. The acceptability and intentionality (for the cows not the commercial) are violated because the cows misunderstand the new cow. Informativity is achieved for example the website link exists in this commercial.

\section{The fifth commercial:}

A rural wooden hut with the sounds of a rooster and birds, the camera shifts to inside the hut to see a cow which yawns, another cow says "good morning". Then the camera refocuses on the rooster and its sound which makes the first cow angry. In the end of this commercial the rooster is being thrown outside the hut in an aggressive way. The narrator ends the commercial with "great cheese comes from happy cows... and happy cows from California... real California cheese.. it's the cheese."

\footnotetext{
${ }^{3}$ See www.disborads.com

${ }^{4}$ See bunnygurl.blogspot.com
} 
This commercial which lasts for thirty second, shows the spoiled cows who do not want to wake up early, for example: the first cow says: "what's the hurry". This idea almost exists in all Real California Cheese Company. This commercial as the previous one has the website link for the company.

\section{International companies:}

The researchers want to explain two kinds of foods' commercials which are Snickers and Philadelphia cheese which exist in the two parts of the world trying to show the similarity and the differences.

\section{Philadelphia cheese:}

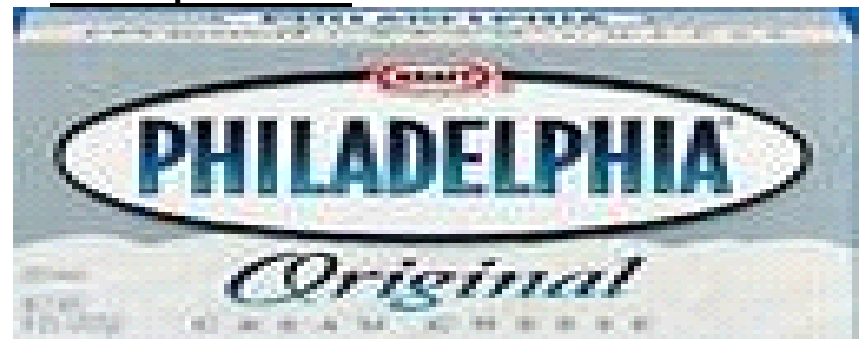

Starting with the Philadelphia cheese, the commercials in America are two kinds; the first commercial represents women in the sky wearing white clothes showing them as angels who care for their bodies so they eats Philadelphia cheese because of the law fat that it causes comparing it with other kinds of cheese. The second kind of Philadelphia cheese focuses on the cheese alone to show the brightness of the cheese trying to reflect its taste from the picture and the sound of the narrator who explains the ingredients with a special tone trying to persuade people that this cheese is unimaginable.

This kind of commercial exists in the Arabic part of the world but because Philadelphia`s company tries to sell their products to the Gulf area so the first kind exists in the Arab part but with some changes for example the angel women are changed with a whole family; father, mother and children who eat the cheese and because of its taste it will make them feel that they are in the sky which implies somehow the law fat in this product and the happiness that will cause. However, in the west part of the world there is a commercial, "there is one cheese... taste better... with wine..." this commercial shows this cheese with green grapes on the same plate with a bottle of wine. So, this kind of commercial represents the west culture more than the Arab culture because as said before this company tries to sell their product to the Gulf area so they will be restricted with the tradition and the culture which prevents drinking.

\section{Snickers chocolate:}

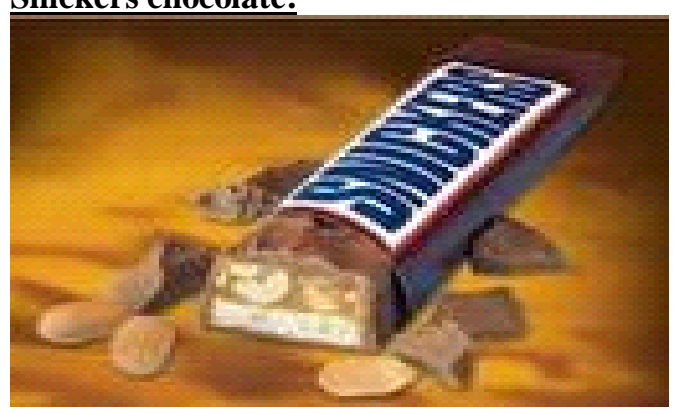

The researchers have taken the 2011`s commercial into consideration only to compare and contrast between the two cultures. In 2011 there is only one advertisement for Snickers in Arabic which is thirty one seconds only; however, it represents the stereotype that women have less power than men. This commercial is about two guys and one old woman try to push the car in order to make it work and while they are pushing the old woman keeps complaining to show that she is doing something is higher than her ability. In that moment, another guy gives her a Snickers to eat and suddenly this old lady turns to be a Guy originally but because this guy is hungry he turns to be an old woman as the narrator says that (enta mo enta w enta jo3an) which means "you are not you when you're hungry".

This commercial tries to be universal in the Arab part; however, the guys are Egyptians who are unknown for the Arab part but the guy who turns to be an Egyptian old woman, but this woman is a very known actress who almost known in the whole Arab`s part, finally the narrator uses an accent from the Gulf part trying to make more acceptable in the Gulf area. This idea exists too in the second part of the world, the researcher has found two commercials for Americans and these commercials have the same idea but in different situation; a group of guys who are playing super bowl with an old woman who cannot handle their roughness at the game so one of the guys calls this old woman "Mike" and tells her that "you are playing like Betty White out there" and she answers him that "yes that is what your girlfriend says" in that moment there is a young lady who calls this old women "hey baby" and asks her to eat a Snickers and from the first bite this old woman turn to be a young man. The narrator says "you are not you when you are hungry" then "Snickers satisfies" the narrator means that Snickers satisfies the hunger. 
Snickers' chocolate ingredient as roasted peanuts requires the advertisements to have some roughness unlike for example Galaxy chocolate which is smoother than Snickers. So, one can notice that Galaxy commercials use women only to represent the chocolate as if the receiver for this chocolate are women only, so as a researcher I would like to recommend researchers to make a survey to see if the commercial affects the receiver or not for example; do women prefer Galaxy more than Sinkers because Galaxy`s commercials are more connected with women unlike Snickers which is connected with roughness.

\section{CONCLUSION}

In conclusion, the reader can notice that advertisements' language does not always achieve the standards of textuality. In advertisements the focus is on intentionality because commercials are produced to persuade costumers to buy the product. Also, advertisements should give an amount of information which is more likely about the quality of the product and this amount varies from one company to another and from one culture to another as the website link. However, the two companies` commercials do not have any information about the price, ingredients or where can they be found. In addition, the reader can notice that cohesion and coherent are achieved most of the time, but they also can be violated. Also, the language of the advertisements tends to use a lot of adjectives to describe the product for example "great". According to cultures, the reader can notice that there are similarities and differences; in the similarity case, for example "snickers" has the same theme in both cultures. However, the differences for example; the Almarai commercial for Ramadan or the use of proverbs cannot exist in the Western part in contrast the cheese with wine commercial cannot exist in the Arabs world especially at the Gulf Area. Also, the Arabs`commercials are more direct than the American`s but the Americans have more humor than the Arabs in their commercials, however, Almarai`s commercials represent the ideal family which spend happy time with each other trying to make it more connected to audience' life, also they are more emotional.

\section{REFERENCES}

[1] Agatep-Valmoria, Myra Vina. (2007). Product Catigories and Information Content of Television Advertisements in the Philippines. Philippine Management Review, Vol. 14, 145-165.

[2] Ahmed, Niaz. (1996). Cross Cultural Content Analysis of Advertising; from the United States and India. University of southern Mississippi. https://www.bookpump.com/dps/pdf-b/1120842b.pdf. Retrieved on 4/3/2019.

[3] Bansal, Sanjeev. (2010). A Cultural Analysis of American and Indian Advertisements. ACCMAN Journal of Management Studies 2 (1), 1-12

[4] Bezuidenhout. (1998). A Discursive-Semiotic Approach to Cultural Aspects in Persuasive Advertisements. http://ilze.org/semio/. Retrieved on 4/3/2019.

[5] Downing, Laura Hidalgo. (2000). Text World Creation in Advertising Discourse. Revista Alicantina de Estudios Ingleses 13, 67-88.

[6] Gully, Adrian. (1996-97). The Discource of Arabic Advertising. Journal of Arabic and Islamic Studies 1 https://www.lancaster.ac.uk/jais/volume/docs/vol1/1_001-49_GULLY07.PDF. Retrieved on 4/3/2019.

[7] Jabeen, Aliya. (2011). Promoting Culture Through Advertisements. EzineArticles.

[8] Magalhaes, Izabel. (2005). Critical Discourse Analysis and The Semoiotic Construction of Gender Identities. D.E.L.T.A, 179205.

[9] Nilssen, Tore. Lars Sorgard. (2001). Strategic Informative Advertising in a TV- Advertising Duopoly. http://www.sv.uio.no/econ/english/research/unpublished-works/working-papers/pdf-files/2000/Memo-17-2000.pdf. retrieved on $4 / 3 / 2018$.

[10] online sites which were retrieved on 4/3/2018: www.lordofthebrush.com, www.sportsnetwork.com, www.disborads.com, bunnygurl.blogspot.com.

[11] Perry, Vanessa. Carol Motley and Peggy Lewis. (2008). Dreams and Taboos: a cross cultural comparison. Journal of International Consumer Marketing, 22: 2, 199 - 212.

[12] Yang, Shen. (2006). The Translation of International Advertisements: A Cross-cultural Perspective. US-China Foreign Language. 4(11).

Wafa Moh'd Qtaishat is an Associate Professor of Arabic Language at the University of Jordan. She obtained his PhD from the University of Jordan in 1996. She has published extensively in the areas of syntax, linguistic analysis, discourse analysis, and contrastive linguistics.

Dania Ahmad Al-Hyari is a PhD student of Linguistics at the University of Jordan. Her academic research focuses on Linguistics. She is currently writing her Ph.D thesis in Linguistic Analysis of shop signs in Jordan. 